\title{
Image of the month: Alternating bifid pulse - a novel manifestation of low cardiac output states
}

\author{
Authors: Krishna Kumar Mohanan Nair, ${ }^{A}$ Arun Gopalakrishnan, ${ }^{B}$ Sonali Avinash Inamdar, ${ }^{C}$ Sanjay Ganapathi, ${ }^{D}$ \\ Harikrishnan Sivadasanpillai, ${ }^{\mathrm{E}}$ Sivasankaran Sivasubramonian, ${ }^{\mathrm{F}}$ Ajitkumar Valaparambil ${ }^{\mathrm{G}}$ \\ and Jaganmohan Tharakan ${ }^{\mathrm{H}}$
}

An 18-year-old male with familial dilated cardiomyopathy was admitted with shortness of breath of 1-week duration. On clinical examination, he was tachypnoeic at rest and had tachycardia with regular beat-to-beat variation in the pulse volume. Jugular venous pressure was elevated. The blood pressure was 100/74 mmHg. Cardiovascular examination revealed cardiomegaly and left ventricular (LV) third heart sound. Bilateral fine basal crepitations were noted. 12-lead electrocardiogram showed sinus tachycardia and no significant ST-T changes. Transthoracic echocardiogram showed global LV hypokinesia with LV ejection fraction of $10 \%$. Alternating weak and normal beats with ' $\mathrm{M}$ ' pattern are seen in the radial artery pulse tracing (Fig 1).

Alternating weak and normal beats represent volume abnormality of the pulse due to alternation in the number of cardiac fibres contributing to each systole. ${ }^{1}$ It indicates significant ventricular systolic dysfunction. Bifid pulse with systolic and diastolic peaks represents a character abnormality of the pulse. It indicates low cardiac output state. The incisural notch becomes prominent with respect to the overall arterial

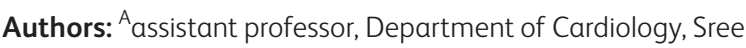
Chitra Tirunal Institute for Medical Sciences and Technology, Thiruvananthapuram, India; ${ }^{B}$ assistant professor (adhoc), Department of Cardiology, Sree Chitra Tirunal Institute for Medical Sciences and Technology, Thiruvananthapuram, India; ' senior resident, Department of Cardiology, Sree Chitra Tirunal Institute for Medical Sciences and Technology, Thiruvananthapuram, India; ' associate professor, Department of Cardiology, Sree Chitra Tirunal Institute for Medical Sciences and Technology, Thiruvananthapuram, India; ${ }^{\mathrm{E}}$ additional professor, Department of Cardiology, Sree Chitra Tirunal Institute for Medical Sciences and Technology, Thiruvananthapuram, India; F professor, Department of Cardiology, Sree Chitra Tirunal Institute for Medical Sciences and Technology, Thiruvananthapuram, India; ${ }^{G}$ professor, Department of Cardiology, Sree Chitra Tirunal Institute for Medical Sciences and Technology, Thiruvananthapuram, India; ${ }^{\mathrm{H}}$ senior professor and head, Department of Cardiology, Sree Chitra Tirunal Institute for Medical Sciences and Technology, Thiruvananthapuram, India *Department of Cardiology, Sree Chitra Tirunal Institute for Medical Sciences and Technology, Thiruvananthapuram, India

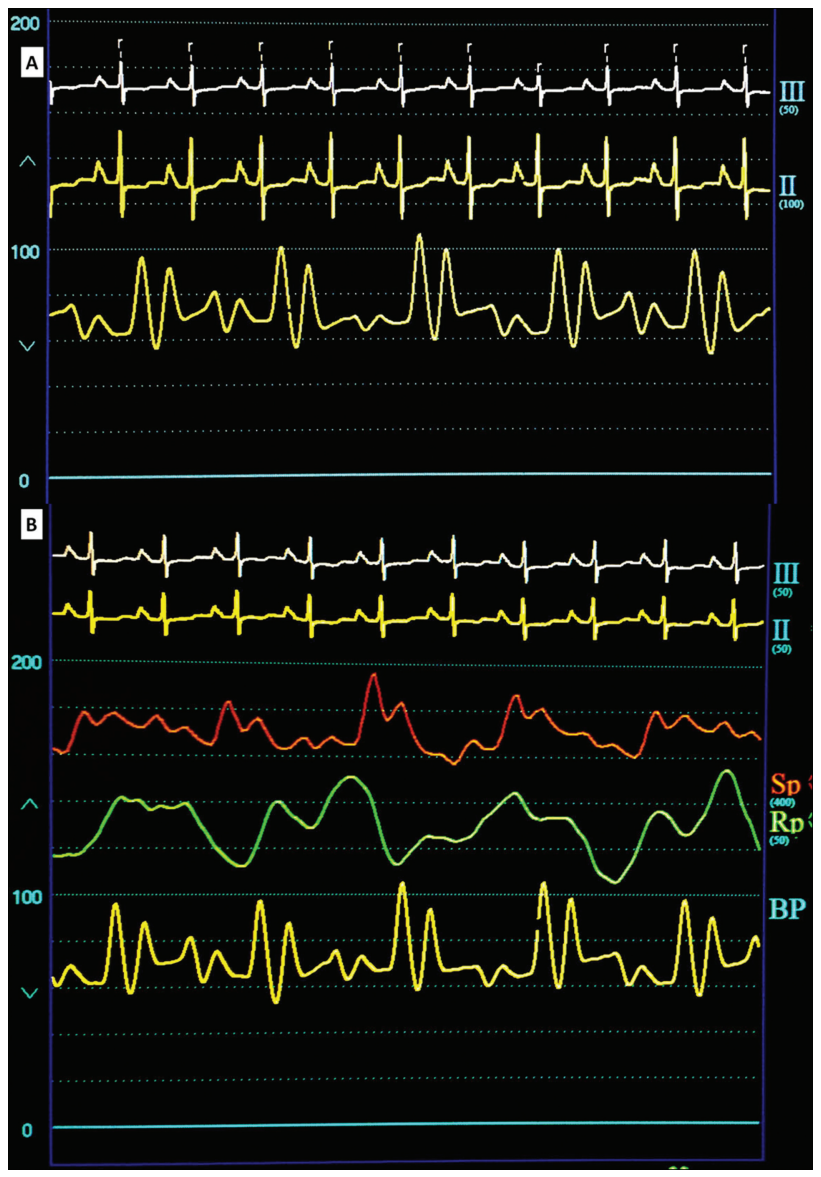

Fig 1. (A) Simultaneous ECG and radial artery tracing; (B) Simultaneous ECG, pulse oximetry recording (red), respirometer tracing (green) and arterial waveform tracing (yellow). ECG = electrocardiogram.

pulsation in low cardiac output state generating the classical M-shaped waveform of the dicrotic pulse. ${ }^{2}$

The radial artery pulse tracing shows simultaneous representation of pulses alternans and pulses dicroticus. The alternating bifid pulse represents significant LV dysfunction 
and low cardiac output state and carries poor prognosis.

Simultaneous representation of these pulse abnormalities has not been described earlier and is reported for the first time.

\section{References}

1 Singh B, Soni A, Kanchanahalli SS, Nanajappa MC. Pulsus Alternans Doppler Demonstration. Circulation 2014;129:1540-1.
2 Smith D, Craige E. Mechanism of the dicrotic pulse. Br Heart J 1986;56:531-4.

Address for correspondence: Dr KKM Nair, Department of Cardiology, Sree Chitra Tirunal Institute for Medical Sciences and Technology, Thiruvananthapuram 695011, India.

Email: kakkam@gmail.com

\section{Royal College of Physicians Museum and Medicinal Garden}

Visit the Royal College of Physicians (RCP) and discover 500 years of medical history in an acclaimed architectural setting.

The RCP is the oldest medical college in England, and since its foundation in 1518 it has built up magnificent collections of books, manuscripts, portraits, silver, and medical artefacts.

Our celebrated Grade I listed headquarters in Regent's Park is the creation of British architect Sir Denys Lasdun and our garden contains over 1,300 plants, each used as medicine around the world over the past 3,000 years.

\section{Guided tours}

We offer guided tours of the building and garden, and welcome bookings for groups of six or more. Refreshments can be booked and tours tailored for special interest groups. Guided tour charges are $€ 5$ per person (refreshments extra).

Royal College of Physicians, 11 St Andrews Place, Regent's Park, London NW1 4LE. Open: Monday- Friday, 9am- 5pm, free entry

Library, Archive and Museum Services

Tel: +44 (0)203075 1543

Email: history@rcplondon.ac.uk

\section{Royal College} of Physicians
Free entry

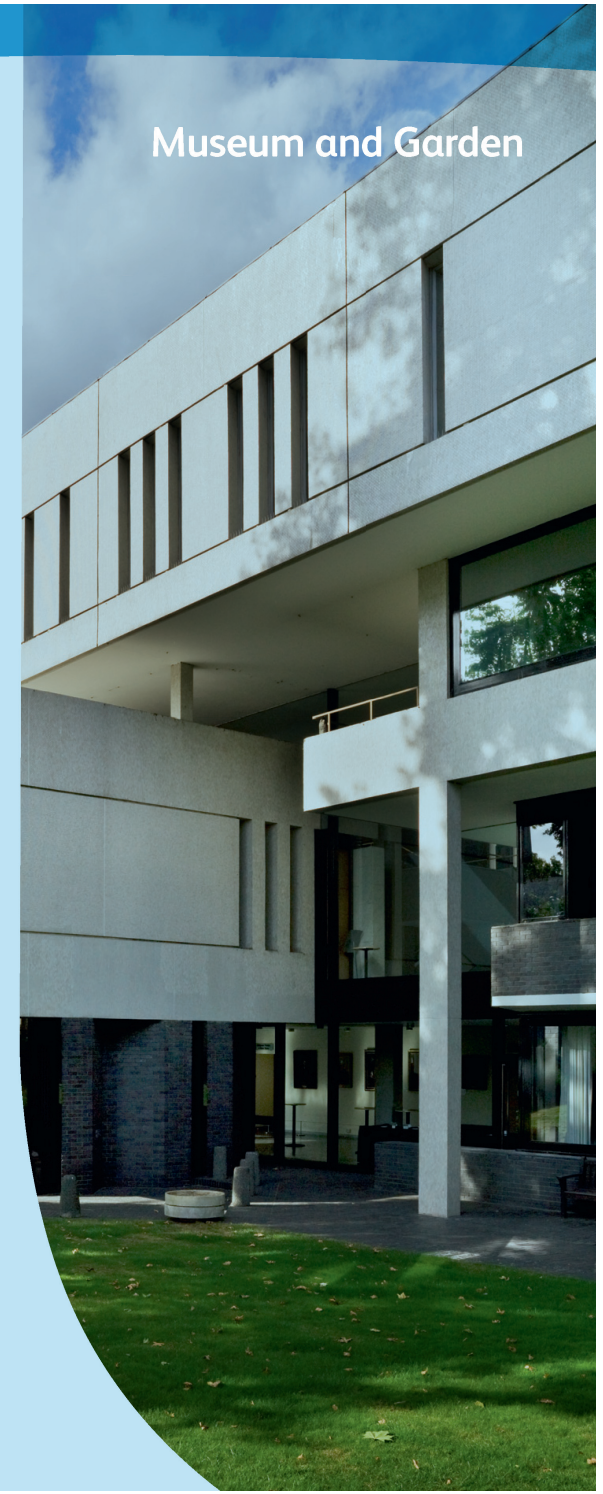

